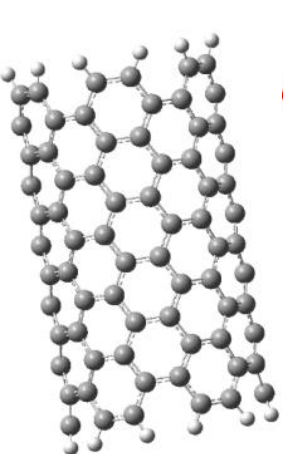

a)

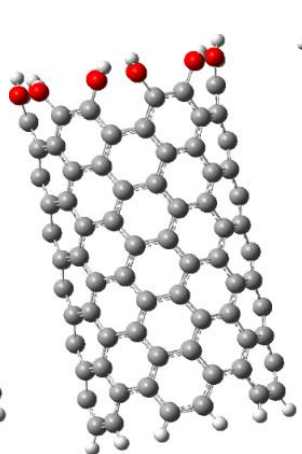

б)

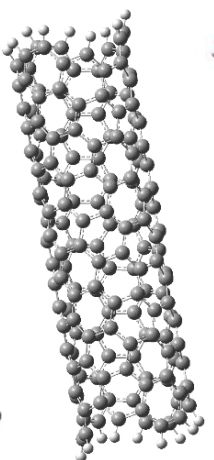

B)

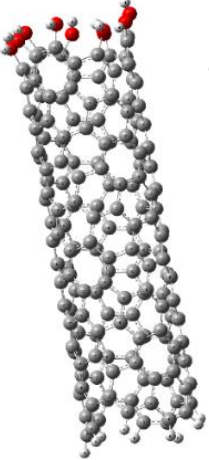

г)

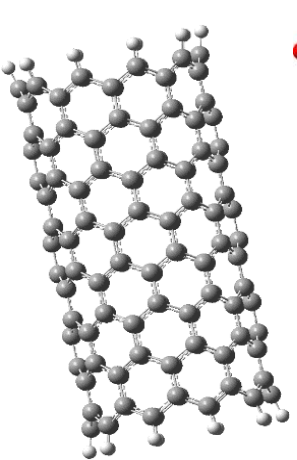

д)

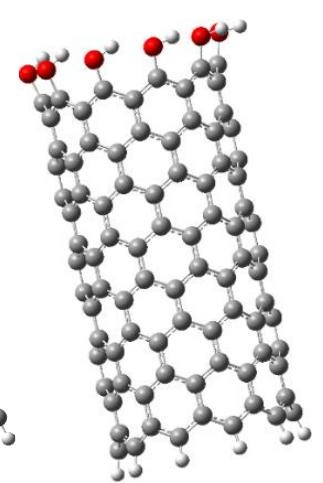

e)

Рис. 1. УНТ, замкнутые псевдоатомами Н (УНТ кластер) размеров $(6,6)(\mathrm{a}),(3,6)($ в), $(0,10)$ (д) и замкнутые псевдоатомами Н и группами ОН (УНТ-[ОН] кластер) размеров $(6,6)(6),(3,6)(\Gamma),(0,10)(\mathrm{e})$

Было установлено, что во всех кластерах центр адсорбции для атомарной сурьмы находится на торце тубуленов. Атом алюминия будет адсорбироваться лишь в одном кластере - УНТ кластер размера $(3,6)$. Адсорбция атома свинца не наблюдалась ни в одном из рассматриваемых кластеров.

1. Маркирующая добавка во взрывчатое вещество, способ ее приготовления, способ определения происхождения взрывчатого вещества и устройство для его осуществления, патент RU 2283823, C06B 023/00, G01J 003/30, G01N 033/22.

2. Патент RU № 2625462.

\title{
MULTI-GRAIN EVOLUTION UNDER SLOW, INTERMEDIATE AND FAST REGIMES OF SOLIDIFICATION IN MULTI-COMPONENT ALLOYING SYSTEM
}

\author{
Galenko P. K. ${ }^{1,2}$, Nizovtseva I. G. ${ }^{1 *}$, Moelans N. ${ }^{3}$ \\ 1) Ural Federal University named after first President of Russia B.N. B.N.Yeltsin, \\ Yekaterinburg, Russia \\ 2) Friedrich-Schiller-Universität Jena, Jena, Germany \\ ${ }^{3)}$ Katholieke Universiteit Leuven, Leuven, Belgium \\ *E-mail: nizovtseva.irina@gmail.com
}

A phase field model of rapid multi-grain growth is developed. Using a model of fast phase transformations [1] and a multi-phase model for polycrystalline growth in multi-component alloying systems [2], the Gibbs free energy change upon crystallization is formulated as driving force for polycrystalline growth. At a fixed pressure and constant temperature, the full Gibbs free energy is presented as a sum of the local equilibrium contribution, which is based on the set of slow thermodynamic variables (concentration and phase field, at a given temperature), and the local non-equilibrium contribution, which is based on the space of the fast thermodynamic variables (diffusion 
flux and gradient flow). Neglecting the change of molar volume between phases and internal stresses, the local equilibrium contribution is defined by the contribution from bulk phases (grains) and the contribution from the diffuse interface (the latter takes into account takes into account the additional energy associated with the relaxation of the diffusion flux and gradient flow).

The evolution equations for fast crystallization are written using multi-phase interpolation functions among growing poly-crystallites. The equations for diffusional mass transport and multi-phase evolution are written in a form suitable for numerical and analytical solutions $[3,4]$.

1. Galenko P., Jou D., Phys. Rev. E., 71, 046125-1-13 (2005).

2. Moelans N., Blanpain B., Wollants P., Phys. Rev. Letters, 101, 025502-1-4 (2008).

3. Nizovtseva I.G., Galenko P.K., Alexandrov D.V., Journal of Physics A: Mathematical and Theoretical, 49, 435201-1-14 (2016).

4. I.G. Nizovtseva, P.K. Galenko, Philosophical Transactions A, Royal Society, 376, 20170202-1-15 (2018).

\title{
TRAVELING WAVE SOLUTION OF PHASE FIELD MODEL FOR MULTI-GRAIN SYSTEMS
}

\author{
Galenko P. K. ${ }^{1,2}$, Nizovtseva I. G. ${ }^{1 *}$, Moelans N. ${ }^{3}$ \\ 1) Ural Federal University named after first President of Russia B.N. B.N.Yeltsin, \\ Yekaterinburg, Russia \\ ${ }^{2)}$ Friedrich-Schiller-Universität Jena, Jena, Germany \\ 3) Katholieke Universiteit Leuven, Leuven, Belgium \\ *E-mail: nizovtseva.irina@gmail.com
}

Using a new phase field model for fast polycrystalline crystallization [1], an analysis of fast and slow crystallization regimes is provided using analytical methods suggested in Refs. [2,3]. Fast regimes of crystallization are analyzed when the crystal growth velocity is of the order of or greater than the solute diffusion speed in a bulk metastable phase. The latter regime represents diffusionless (chemically partitionless) crystallization, when the grains are growing with the initial nominal concentration. In the limiting slow crystallization regime, the developing model [1] is reduced to the equations and solutions, as obtained by the quantitative and thermodynamically consistent multi-phase field model $[4,5]$.

Figure 1 shows the traveling wave velocity for the various relaxation time $\tau$ for the gradient flow of the phase field. Such a behavior of $V(\Delta G)$ is consistent with the data of numerical molecular dynamics simulation [6] and recent advancements on kinetics of fast interfaces [7]. The difference between velocities for different $\tau$ occurs at moderate and large values of driving forces, namely, at $\Delta G>0.2$. At small $\Delta G$, the influence of relaxation time $\tau$ is negligible. 